\title{
OBSERVATIONS ON MEDICAL PHOTOGRAPHY
}

WITH SPECIAL REFERENCE TO SKIN, DISEASES

HOWARD FOX, M.D.

NEW YORK

Time is generally lacking for the average physician to become an expert photographer unless he chooses to take up the photographic art as a hobby. I have long been convinced that professional photographers cannot, as a rule, take satisfactory medical photographs. The difficulty lies in posing the subject, as the professional photographer is seldom able to realize exactly what is desired by the physician. This is particularly true in the case of skin diseases. It is for those who desire to make photographic records of their own cases that the following observations, based on personal experience, have been recorded.

Of the various sources of illumination, diffused daylight is in many ways most satisfactory. Direct sunlight, however, is to be avoided except for taking colored photographs (Lumière plates) when the exposure is necessarily long. Daylight photography has its disadvantages, as a properly lighted studio, which is necessary to produce the best results, is seldom at the physician's disposal. It is also slow and requires a great deal of experience, owing to the change of light, properly to judge the time of exposure.

There are several sources of artificial illumination which are used for photography; namely, flashlight (magnesium powder mixture), electric light (studio lamp), and the Cooper Hewitt lamp (mercury vapor). As I have had no personal experience with the Cooper Hewitt lamp, it will not be considered.

Flashlight is perhaps the most desirable form of illumination, if conditions are such that the resulting smoke can be properly removed. If it is desired to take several pictures at one sitting, the ordinary flash bag, which must be emptied after each exposure, is not very convenient. The most feasible method, as suggested to me by Dr. George M. MacKee, is to have a large canvas or metal drum above the flash which collects the rising smoke and leads it outdoors by pipes. A suction pump may be necessary to aid in carrying out the smoke effectively. It is possible at times to connect the pipes with a vent leading to the roof, and not merely to carry the smoke out of the nearest window and allow it to settle as a fine white dust on the windows of an office or apartment beneath. One great advantage of a flashlight is that it can be fairly well standardized by using for each exposure the same 
aperture, the same amount of flashpowder, and the same distance of the subject from the camera. As a flash is instantaneous, it is naturally most suitable for restless subjects, such as children, or for parts of the body which are difficult to immobilize, such as the tongue, abdomen.

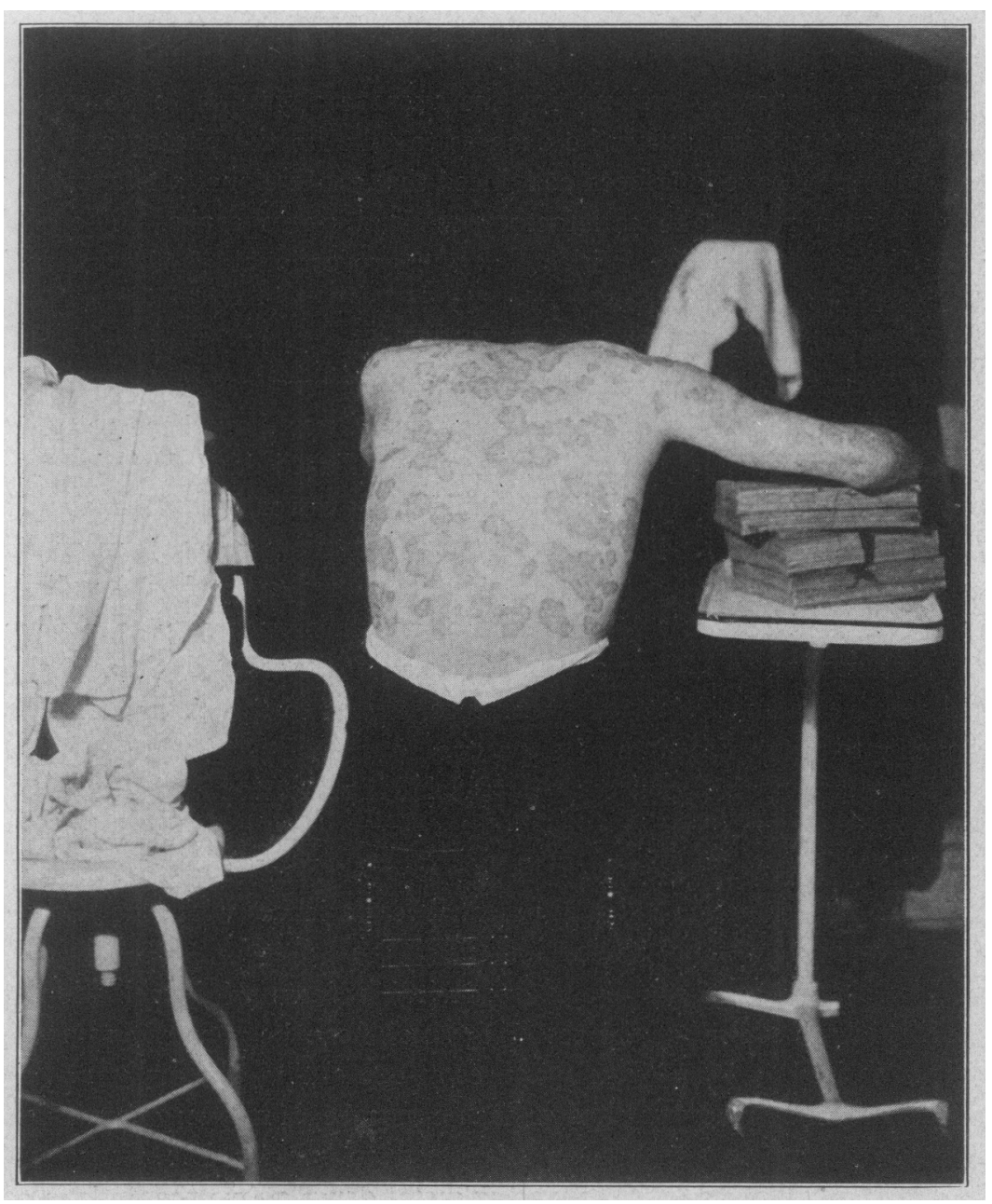

Fig. 1.-Improper posing of subject; area of body too small, head bent forward. arm outstretched, and background filled with inartistic and distracting oljects. Electric light and 7-inch (focal distance) lens were used. Case of psoriasis.

genitals, etc. Another great arlvantage of flashlight is the intensity of illumination, allowing a very small aperture, which increases the depth of focus. 
The so-called studio lamp is a 1,000 watt nitrogen lamp with a blue glass bulb, enclosed in a metal reflector. This is operated on an ordinary 110 volt, direct current. It is a simple and cleanly source of illumination, and one used to best advantage in photographing small

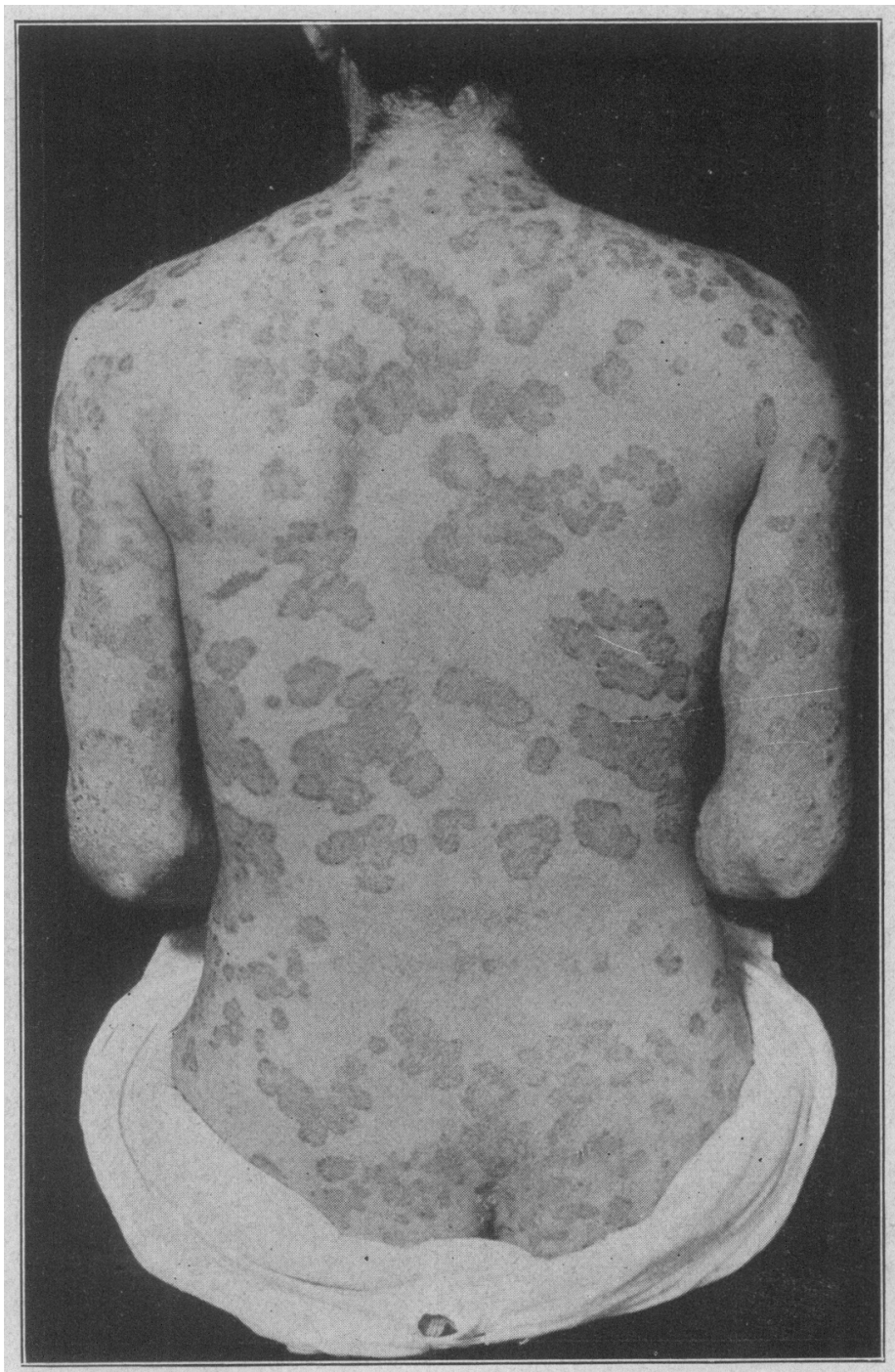

Fig. 2.- Same subject as in Figure 1, properly posed; head erect, shoulders scuared, arms falling evenly, clothing neatly arranged. Illumination and lens same as in Figure 1.

areas of the body, such as the head, hands, feet, etc. Like daylight, its action is slow in comparison with flashlight. As the light is rather concentrated, it casts strong sharlows, which, however, can be aroided 
by using a black background. Unlike daylight, this source of illumination is constant and admits of a certain amount of standardization in making expostures.

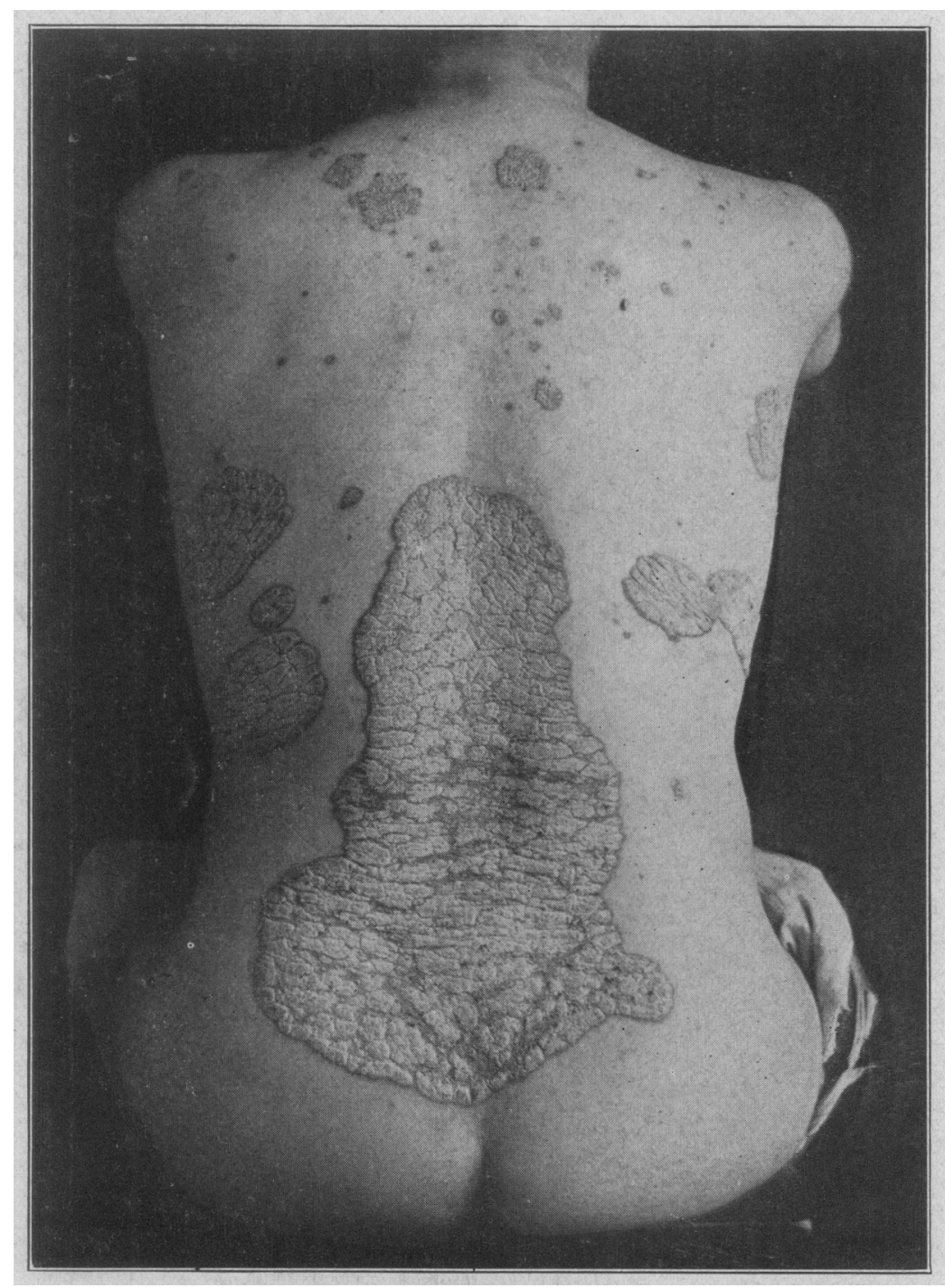

Fig. 3.-Proper pose; body erect; probably not so satisfactory or natural as with arms at side. Photograph by daylight; 19-inch lens. Case of psoriasis.

\section{THE SELECTION OF PROPER LJENSES}

In selecting a lens, it is necessary to consicler quality, focal distance, and speed. A good quality of lens, with the necessary corrections for astigmatism and other defects, can now be obtained from a number of 
high class manufacturers. To understand better these brief remarks on lenses, explanations are herewith given for those who have not had occasion to stucly the subject.

The focal distance of a lens is roughly the distance from its center to the ground glass, when an image at infinity (100 feet or more) is sharply focused (on the ground glass). The speed of the lens depends on the ratio of its diameter to the focal distance. To be exact, the speed is proportional to the square of the effective aperture divided by the focal distance. The greater the diameter of the lens, and the shorter its focal distance, the greater will be the resulting speed. Depth

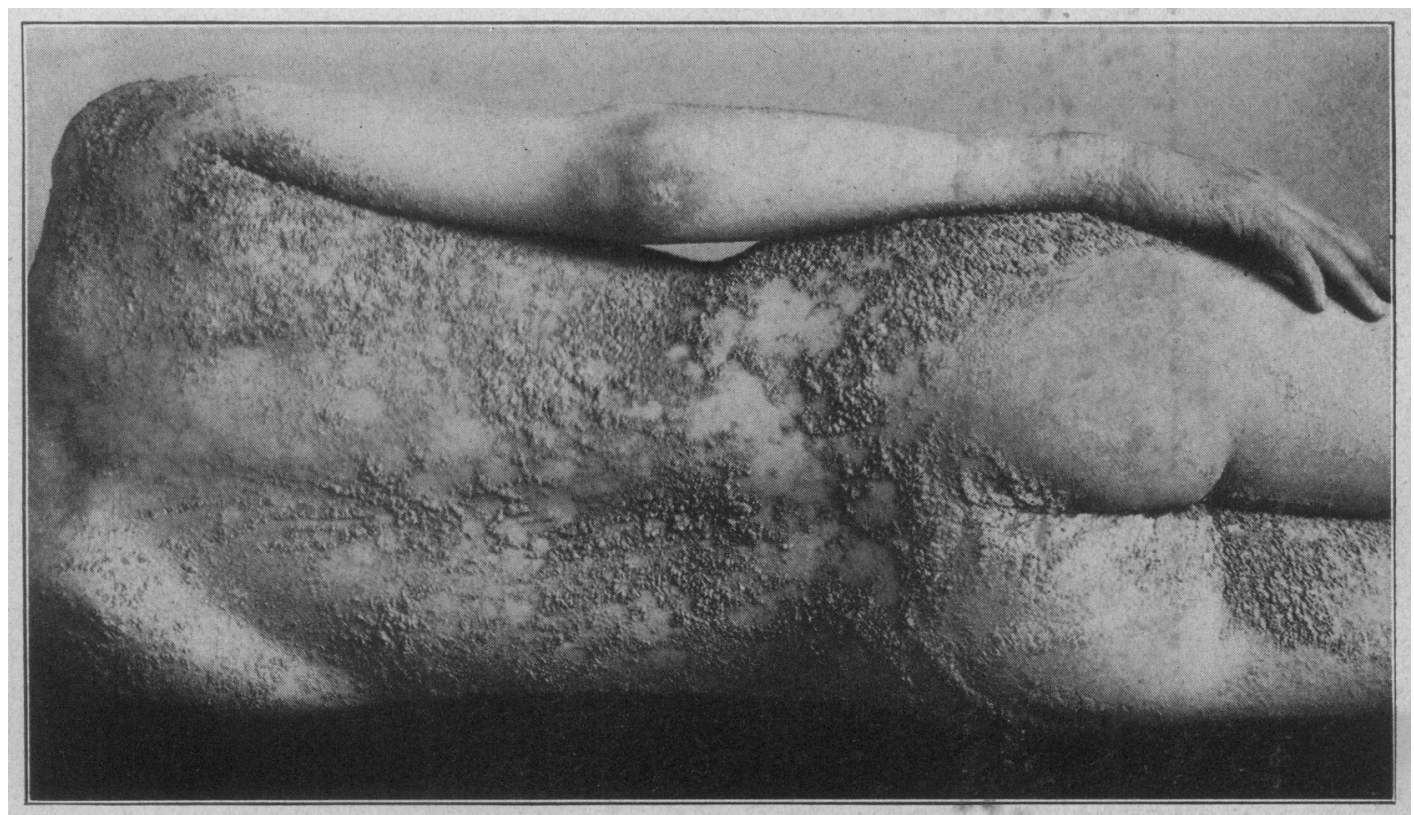

Fig. 4.-Subject lying horizontally on table; suitable position for children or restless individuals; cloth beneath subject too dark; i. e., too much contrast. Gray cloth would have been preferable. Photograph by daylight; 19-inch lens. Case of ichthyosis hystrix.

of focus refers to the range of sharpness forward and back of the object; $i$. e., the ability of the lens to bring points in different planes sharply into one focus at the photographic surface.

To obtain the finest pictures of portions of the human body, it is necessary to use a lens of long focal distance (from 18 to 20 inches). This, however, lessens the speed, unless the lens has a large diameter, which makes it large and bulky, and greatly increases the cost. There is no doubt, lowever, that a lens of long focal distance (with the subject necessarily at a long distance from the camera) gives pictures 
with the least distortion of perspective. This is shown by the finest photographs taken by my father, Dr. (ieorge Henry Fox, with a Dallmeyer lens of 19-inch focal distance. The chief objections, from a practical standpoint, to a lens of long focal distance is that a long gallery is needed, and that unless the lens is very large (and correspondingly expensive) it is rather slow. Probably the ideal lens wou'd be a modern anastigmatic lens of 19-inch focal distance, and rapid action ( $F$ 4.5). Such a lens would cost approximately $\$ 450$ at the present time. For practical purposes a good rule to follow is to use a

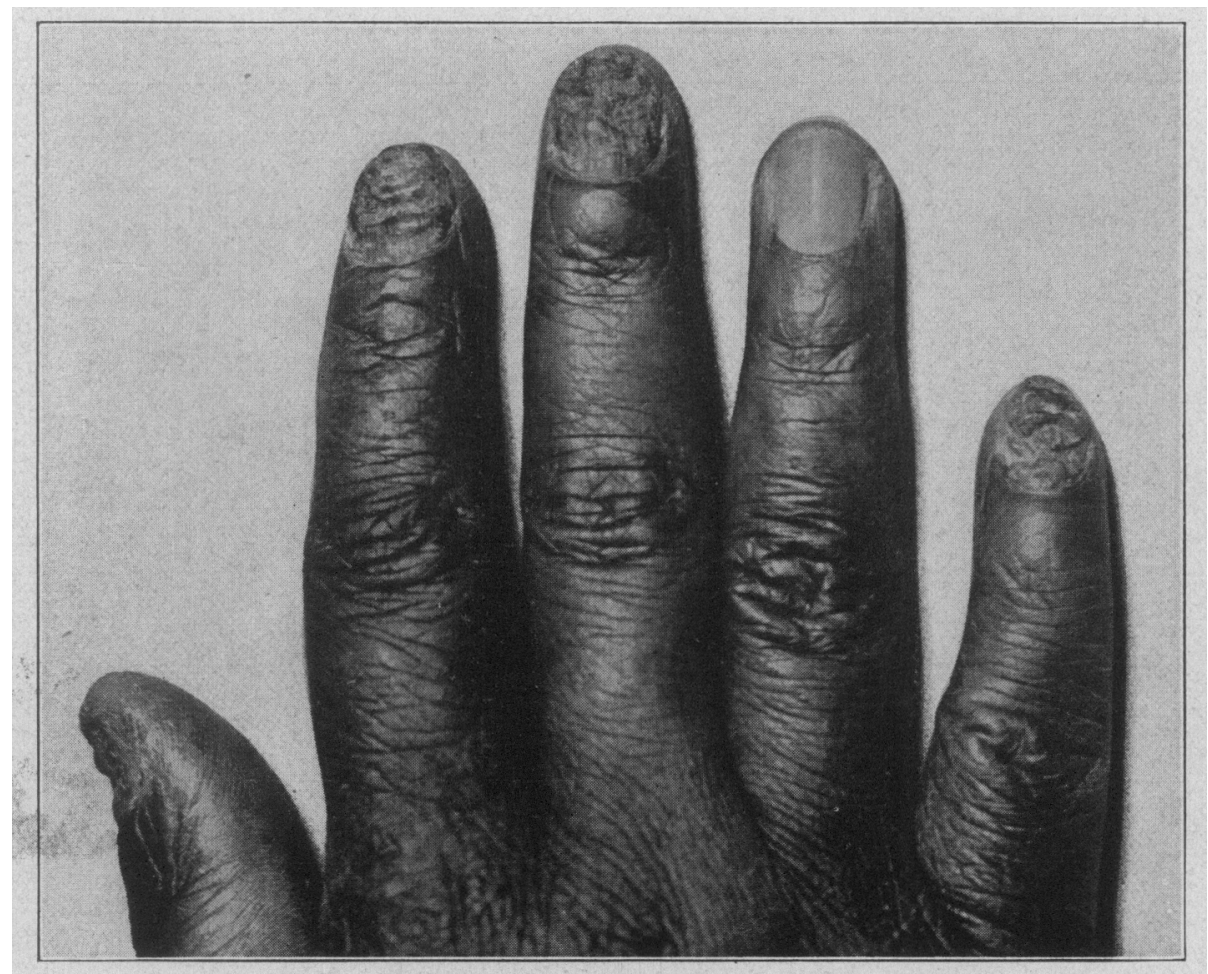

Fig. 5.-Hand against wall, elbow resting on suitable support; fingers look abnormally fat from distortion of perspective, due to too short focal distance of lens. Photograph by electric light; 7-inch lens. Case of ringworm of nails in a negress.

lens whose focal distance is one and one-half times the diagonal of the plate to be covered. Thus, if a 5 by 7 -inch plate is used, the focal distance would be about 12 inches.

\section{TECHNIC}

( ) ne of the essentials for the beginner to learn is the proper posing of the subjest. A good rule is to place the subject in a position that will allow as complete muscular relaxation as possible. When pho- 
tographing the head, there should be a suitable head rest, which, if possible, should not be allowed to appear in the picture. The best photograph of the back is obtained by having the patient straddle a side chair and grasp the back of the chair with both hands, the head being erect and the shoulders sloping evenly. When photographing a hand it is advisable to rest the entire forearm on some suitable flat surface.

There are many who think that if the lesion in question is properly reproduced the artistic aspect of the picture can be entirely disregarded. Thus many otherwise excellent photographs are injured by careless posing of the patient, or by allowing various extraneous objects to appear in the picture, distracting the attention from the disease or deformity that is being portrayed. Disheveled hair or clothing, head rests, furniture, flower pots or other "scenery" in the background, all offend the eye and lessen the artistic value of the picture. A mistake

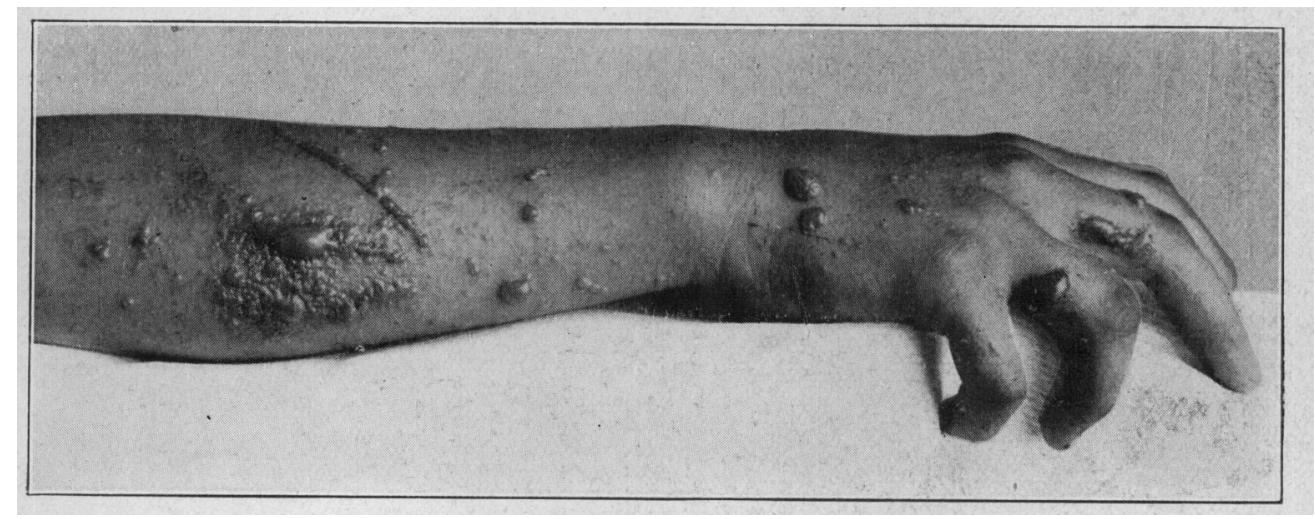

Fig. 6.- Proper pose to show extensor surface of forearm and hand; parts at rest. muscles relaxed; cloth under arm too white; i. e., gives too much contrast. A gray cloth would have been preferalble. Photograph by daylight; 19-inch lens. Case of rhus dermatitis.

that is frequently made is to have either too much or too little border. The tendency is generally to have too little border, as a result of attempting to make the picture as large as possible. Another practice that is subject to severe criticism is that of photographing too limited an area, with the result that it is difficult or impossible to recognize the anatomic landmarks. In many such pictures it is hard to distinguish between an arm or a thigh unless one of the neighboring joints is included. Photographs of a breast or a buttock may likewise be indistinguishable if the region that is included is too limited.

Next to posing the subject the greatest difficulty is to judge properly the time of exposure. This applies chiefly to daylight photography where weather conditions and time of day, as well as time of year, 
must be taken into consideration. In the case of artificial light, this can be more or less standardized. It has generaily been my practice to make two exposures when working by daylight or electric light, and a single one when photographing by flash light.

The choice of a camera is not a matter of great importance, though it is preferable to have it mounted on a solid, movable stand instead of on a tripod. The choice of a studio, however, is of great importance for daylight photography, as a properly constructed sky'ight (preferably with northern exposure) is needed. A black cloth may be used for a background, though I think that the use of black, or of w'lite, causes too much contrast for this purpose. I prefer a wall painted a "battle-

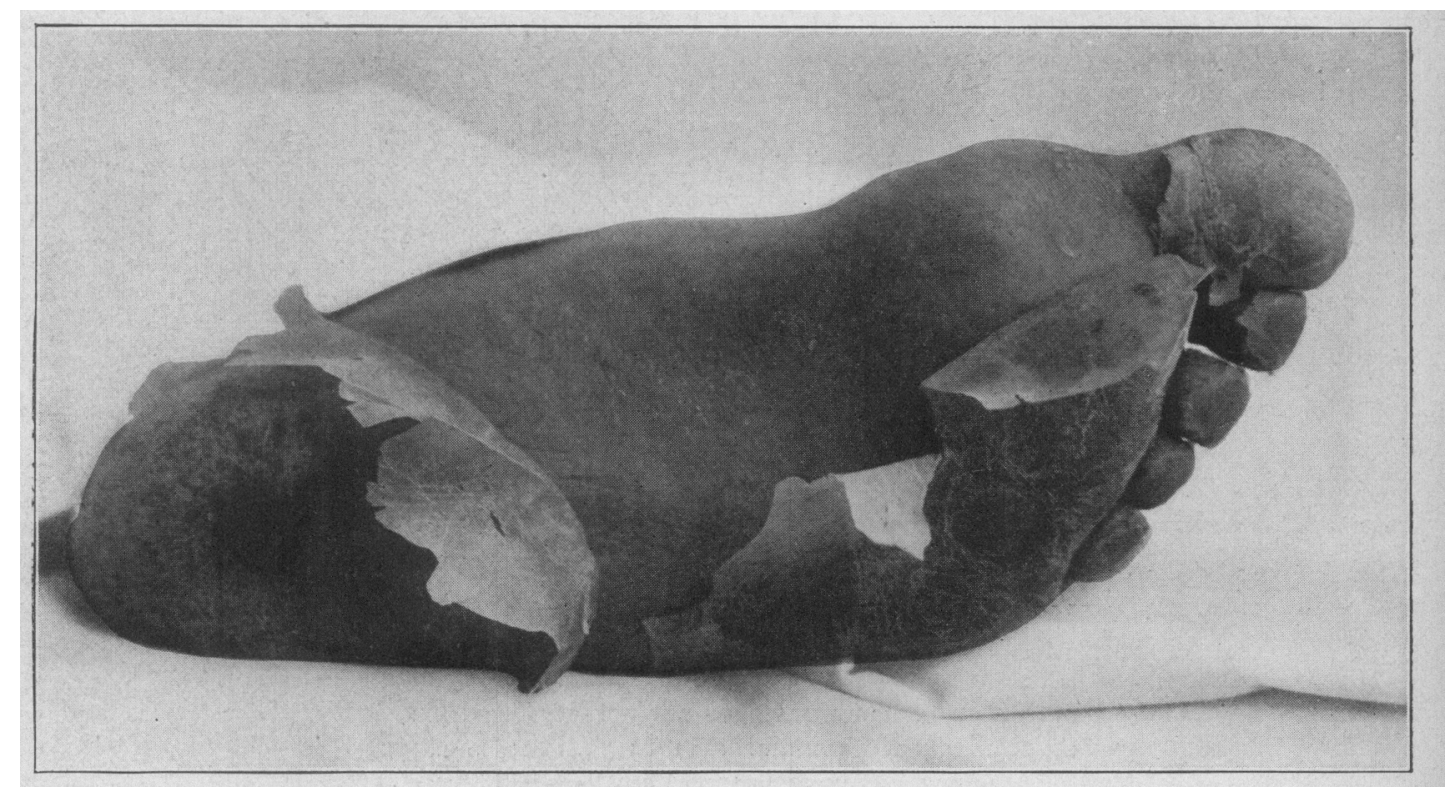

Fig. 7. - Satisfactory pose of foot draped to show sole alone. Photograph by daylight; 19-inch lens. Case of scarlatinal desquamation on sixteenth day (taken at Willard Parker Hospital).

ship gray," or a large piece of canvas. Small pieces of cloth to drape a localized area should also be of a similar neutral color, and the weare of the cloth should be as fine as possible. Reflecting side screens are of value, especially for flashlight work.

Routine developing and printing can fortunately be left to an assistant, or to any good commercial photographer. The best prints for reproduction (halftones) are probably those which are made on glossy printing paper. If this is not obțainable, a good substitute is provided by a glossy developing paper. Blueprint paper for photographic work is unobtainable at present. It can, however, be made 
without much trouble by using a mixture of potassium ferricyanid and iron and ammonium citrate (supplied commercially in powder form). While such prints are not suitable for reproduction, they are very convenient for an index of a collection of photographs.

In the choice of photographic plates, speed, color value, and size must be considered. The plates should be reasonably fast, and if

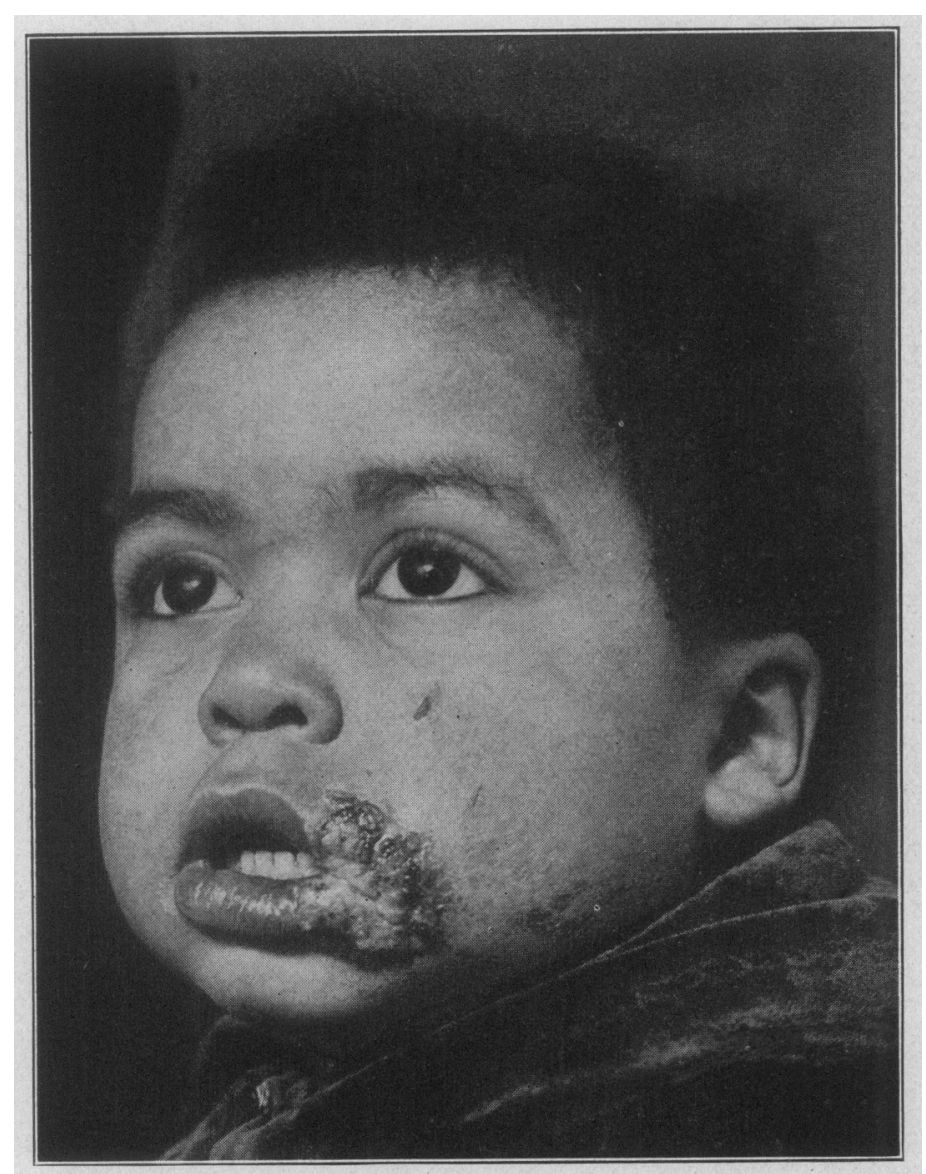

Fig. 8-Photograph by flashlight; 7-inch lens. Case of hereditary syphilis.

orthochromatic they will give the best color values. I feel that it is best to adopt a standlard-sized plate and one that is not too large. Like my father, 1 lave used 5 by 7 -inch plates for many years. A larger plate than this is unnecessarily expensive, and harder to handle and file. When the photographic collection becomes large, it is convenient to file the negatives in boxes, placing them in alphabetical order, on encl, as in the vertical filing system of papers. 
My experience in color photography (Lumière plates), which naturally appeals to the dermatologist, is limited. The plates require a long exposure, are expensive and, what is of greatest importance, cannot be reproduced on paper.

\section{CCNCLUSIONS}

1. Satisfactory medical photographs cannot be made by the average professional photographer, as he is ignorant of the exact anatomic condition which is desired to be reproduced.

2. To obtain a collection of good medical photographs it is generally necessary for the medical man to learn at least to pose the patient, and to make the exposure himself.

3. Developing and printing can be satisfactorily done by professional photographers.

4. Daylight, flashlight and electric light (studio lamp) are all suitable sources of illumination, though each has certain advantages and disadvantages.

5. It is urged that care be taken to make artistic as well as anatomically accurate photographs.

6. The lens should be of good quality and of reasonably long focal distance, if the length of the gallery permits.

7. A standard size should be adopted for photographic plates, 5 by 7 inches having been found very satisfactory and convenient.

616 Madison Avenue. 